\title{
A COMPETÊNCIA EM INFORMAÇÃO COMO UM \\ FATOR RELEVANTE PARA A ORGANIZAÇÃO DO CONHECIMENTO: INTER-RELAÇÃO ENTRE PADRÕES BELLUZZO E AS CATEGORIAS DAS TAXONOMIAS DE BLOOM NA ORGANIZAÇÃO DO CONHECIMENTO
}

The Information Literacy as a relevant factor to Knowledge Organization: an interrelation between standards Belluzzo and categories of Blomm's taxonomy in the knowledge organization

\section{Selma Letícia Capinzaiki Ottonicar (1) Isabela Santana de Moraes (1) Walter Moreira (1)}

(1) UNESP - Univ Estadual Paulista. Departamento de Ciência da Informação-Marília. selma.leticia@ hotmail.com, isabela@marilia.unesp.br, walter.moreira@marilia.unesp.br

\begin{abstract}
Resumo
O presente artigo tem como objetivo compreender a competência em informação como um fator importante no processo de organização do conhecimento. Os procedimentos metodológicos são desenvolvidos a partir de uma revisão de literatura sobre Organização do Conhecimento e a Taxonomia de Bloom, e também, sobre a Competência em Informação e Padrões Belluzzo para medir esta competência e realizar a inter-relação desses domínios. Esse trabalho é um tema importante para a ciência da informação, demonstrando a interdisciplinaridade entre a competência em informação e a organização do conhecimento, temas estudados, normalmente, de maneira isolada pela área da Ciência da Informação. Como discussão apresenta-se uma adaptação da Taxonomia de Bloom aplicando-a ao profissional da informação, que objetiva o desenvolvimento cognitivo e é interpretada como um processo de organização do conhecimento, assim como sua inter-relação com os padrões Belluzzo que é utilizado para medir a competência em informação. Por fim, conclui-se que essa inter-relação proposta demonstra que a competência em informação contribui com a atuação do profissional da informação no processo de organização e representação do conhecimento, proporcionando a capacidade de acessar, avaliar, usar, contextualizar e flexibilizar os conhecimentos para melhor representar e organizar outros conhecimentos.

Palavras-chave: Organização do Conhecimento; Competência em Informação; Taxonomia de Bloom; Competência do Profissional da Informação.
\end{abstract}

\section{Introdução}

Espera-se que o profissional da informação, no exercício de suas funções, desenvolva habilidades e capacidades para organizar e representar o conhecimento. Os usuários das unidades de informação apresentam diver-

\begin{abstract}
This paper aims to understand the information literacy as an important factor in the organization of knowledge process. The methodological procedures are developed from a literature review on the Organization of Knowledge and Bloom's Taxonomy and on competence in Information and Belluzzo's patterns to measure this power and carry out the interrelationship of these domains. This research is an important issue for information science, demonstrating the interdisciplinary competence in information and knowledge organization, topics usually studied in isolation by the area of Information Science. An adaptation of Bloom Taxonomy applied to the information professional is presented as discussion. It aims at the cognitive development and is interpreted as a process of organization of knowledge as well as their relationship with Belluzzo's patterns, which are used to measure competence in information. Finally, it is possible to conclude that this interrelationship proposed demonstrates that the information literacy contributes to the performance of the information professional in the process of organization and representation of knowledge, providing the ability to access, evaluate, use, contextualize and make knowledge more flexible to better represent and organize other knowledge.
\end{abstract}

Keywords: Knowledge Organization; Information Literacy; Bloom's Taxonomy; Information Professional Competences.

sas necessidades informacionais cujas identificações tornam-se condição para que o conhecimento seja organizado de maneira eficiente e eficaz. As habilidades e capacidades voltadas à busca e ao uso da informação são entendidas como competência em informação. Considerando-se que a organização do conhecimento é 
uma tarefa profissional complexas (pela quantidade de variáveis que envolve) e que para seu pleno cumprimento são requeridas competências informacionais específicas, coloca-se como problema da presente pesquisa o seguinte: de que maneira a competência em informação pode contribuir com a organização do conhecimento?

O objetivo geral é compreender a competência em informação e relacioná-la como um fator importante no processo de organização do conhecimento.

Esse trabalho é um tema importante para a ciência da informação, demonstrando a interdisciplinaridade entre a competência em informação e a organização do conhecimento, temas estudados de maneira relativamente segregada pela área. Além disso, os resultados demonstram as etapas da organização do conhecimento que podem ser traduzidas pela Taxonomia de Bloom e sua inter-relação com os padrões de competência em informação adequados para o contexto brasileiro, elaborados por Belluzzo (2007).

\section{Procedimentos Metodológicos}

A metodologia escolhida para desenvolver o arcabouço teórico foi a pesquisa teórica-reflexiva, já que se adéqua melhor com os objetivos e justificativa que é constituída pela união dos temas organização do conhecimento e competência em informação, temas estudados separadamente na Ciência da Informação. Além disso, o tema ainda é novo na ciência da informação e necessita de mais pesquisas para possibilitar estudos de caráter mais aplicado.

Realizou-se consulta em artigos de revistas nacionais da área de ciência da informação, livros, capítulos de livros sobre organização do conhecimento e competência em informação, temas centrais para a construção do tema.

\section{Competência em Informação}

Em meados de 1970 surgiu o conceito de competência em informação e nesse mesmo período havia uma intensificação do fluxo informacional e das tecnologias de informação e comunicação. Nessa época havia a preocupação de que as pessoas deveriam se tornar flexíveis para atuar em um ambiente informacional complexo (Mata \& Casarin, 2011).

O profissional da informação ${ }^{1}$, em sua faceta mais negativa, era visto como um indivíduo estático, isto é, que, normalmente, apenas reagia às solicitações de busca, registrando as entradas e saídas de material. Atualmente, ocorreu uma revolução do seu papel social, sendo visto como um ator importante para o desenvolvimento e formação de pessoas bem como para o desenvolvimento científico, tecnológico e cultural de qualquer nação.
Além disso, novas exigências apareceram no mercado e com isso aumentaram as competências do profissional da informação como a criatividade, flexibilidade, capacidade de enxergar as necessidades dos usuários, próatividade, comunicabilidade, entre outras.

Dentre tantas competências necessárias ao profissional destaca-se a competência em informação que antecede qualquer outra competência, pois para desenvolver suas capacidades e habilidades técnicas é primordial que saiba como perceber a necessidade informacional do usuário, acessar, avaliar e usar as informações de maneira inteligente para alcançar seus objetivos.

Segundo Dudziak (2003, p. 28) a competência em informação é definida como:

processo contínuo de internalização de fundamentos conceituais, atitudinais e de habilidades necessário à compreensão e interação permanente com o universo informacional e sua dinâmica, de modo a proporcionar um aprendizado ao longo da vida.

Para Vitorino e Piantola (2009, p. 136), a pessoa competente em informação deveria agregar:

tanto as competências inicialmente previstas pelos bibliotecários quanto uma perspectiva crítica em relação à informação e ao conhecimento e ao seu próprio tempo, na medida em que permitiria uma percepção mais abrangente de como nossas vidas são moldadas pela informação que recebemos cotidianamente. Nesse sentido, os autores ampliam o conceito e o papel social da competência informacional, que seria muito mais do que uma reunião de habilidades para acessar e empregar adequadamente a informação e passaria a funcionar como uma ferramenta essencial na construção e manutenção de uma sociedade livre, verdadeiramente democrática, em que os indivíduos fariam escolhas mais conscientes e seriam capazes de efetivamente determinar o curso de suas vidas.

A partir da citação de Vitorino e Piantola (2009) percebe-se que a competência em informação não se refere apenas ao suprimento das necessidades do usuário, mas é um fator que contribui com a construção do indivíduo como cidadão para atuar de maneira ética no contexto social.

O contexto da aprendizagem relacionado com a competência em informação objetiva:

tornar os estudantes independentes quanto aos processos informacionais, de modo a influenciar no seu desempenho em sala de aula e no desenvolvimento de trabalhos e/ou pesquisas, preparando-os para agregar valor aos conhecimentos adquiridos durante e após a sua formação. No exercício da profissão, o bibliotecário tem um papel fundamental na implantação de programas voltados para o desenvolvimento de competências informacionais nas instituições de ensino de todos os níveis, pois se pressupõe que ele possua uma formação que the propicie o desenvolvimento de habilidades informacionais, tais como seleção, busca, organização, avaliação, disseminação e recuperação da informação, bem como o uso ético da informação (Mata \& Casarin, 2011, p. 120). 
Porém, para contribuir com o desenvolvimento e formação de usuários é importante que o profissional da informação saiba como organizar o conhecimento, ou seja, ser competente em informação a fim de que tanto as informações quanto os conhecimentos sejam dispostos de maneira a contribuir com as necessidades informacionais das pessoas.

Para verificar e medir as características da competência em informação foram desenvolvidos padrões e indicadores em diferentes nações. A pesquisadora Belluzzo (2007) traduziu e indicou padrões e indicadores da competência em informação e da competência midiática adequados ao contexto brasileiro. Assim, selecionaram-se aqueles que estão relacionados apenas com a competência, já que é tema deste trabalho, conforme exposto no apêndice deste artigo

Ao introduzir os padrões e indicadores, a competência em informação demonstra que está presente nas diferentes atividades do profissional da informação, dentre elas destaca-se a organização do conhecimento a fim de facilitar o acesso e uso da informação segundo as necessidades do usuário de informação.

\section{Organização do Conhecimento}

O contexto contemporâneo de avanço tecnológico e acesso ampliado à informação, - comparativamente aos períodos anteriores - está favorecendo e estimulando a produção de conhecimento registrado. Assim, faz-se necessária uma rápida e eficiente organização e identificação para facilitar a recuperação e incentivar o acesso e posteriormente desenvolvimento de novos conhecimentos. Por consequência, se faz necessária uma eficaz organização e classificação do conhecimento registrado.

De modo mais genérico, organização do conhecimento é a maneira como são dispostos os assuntos, onde se deseja sua sistematização ordenada. Na ciência da informação, a OC é a área de estudos voltada às atividades de organização, representação e recuperação do conhecimento registrado (Lima \& Alvares, 2012).

A Organização do Conhecimento (OC) é responsável pela ordenação e sistematização do conhecimento registrado, para facilitar a busca, acesso e uso. Faz-se necessária desde que surgiram as primeiras bibliotecas e com o passar do tempo suas técnicas e procedimentos foram se aprimorando para atender as necessidades de cada época. Os instrumentos mais conhecidos utilizados para organização do conhecimento são: classificação, taxonomias, tesauros, ontologias, entre outras. No presente trabalho o foco será no âmbito da taxonomia.

Barité (2001), relaciona dez premissas básicas oferecendo justificativa intelectual para organização do conhecimento, sendo elas:
1- O conhecimento é um produto social, uma necessidade social e um dínamo social;

2- O conhecimento se realiza a partir da informação, e ao socializar-se é transformado novamente em informação;

3- A estrutura e comunicação do conhecimento formam um sistema aberto;

4- O conhecimento deve ser organizado para seu melhor aproveitamento individual e social;

5- Existem muitas formas possíveis de organizar o conhecimento;

6- Toda organização do conhecimento é artificial;

7- O conhecimento se registra sempre em documentos, como conjunto organizado de dados disponíveis, admite usos indiscriminados;

8- O conhecimento se expressa em conceitos e se organiza mediante sistemas de conceitos;

9- Os sistemas de conceitos se organizam para fins científicos, funcionais ou de documentação;

10- As leis que regem a organização de sistemas de conceitos são uniformes e previsíveis, e se aplicam por igual a qualquer área disciplinar.

Afirma-se que o processo de organização também é um processo de mediação, amparados na premissa $2 \mathrm{em}$ que autor discorre que, o conhecimento se realiza a partir da informação e, ao socializar-se, é transformado novamente em informação. Desta forma, os profissionais da informação participam ativamente como mediadores, socializando o conhecimento e sua circulação através de processos de disseminação de informações e organizando-o por meio de instrumentos adequados para representar e organizar o tema de seus documentos.

Pode-se afirmar que o processo de organização é mediação e, como citado no capítulo anterior, a competência em informação facilita o processo do mediador. Podese inferir, então que um profissional da informação com competência em informação, realiza uma melhor execução do processo de organização do conhecimento, ou que pelo menos dispõe de mais recursos para sua execução.

Hjorland (2003), divide a organização do conhecimento em dois tipos: a) a organização intelectual do conhecimento, também denominada organização cognitiva, em que se utilizam conceitos, sistemas conceituais e teorias para serem organizados; b) a organização social do conhecimento, que é basicamente a organização em disciplinas, profissões, negócios e grupos sociais.

A taxonomia está ancorada no princípio da organização intelectual, na qual é realizada a organização das informações através do conceito que permite alocar, recuperar e comunicar informações dentro de um sistema de maneira lógica, empregada em navegação de portais institucionais, bibliotecas digitais e também bastante 
difundida no contexto da web semântica. A utilização de taxonomias permite que se estabeleçam padrões de alto nível para a ordenação e a classificação de informação através do uso de mecanismos de herança, com relacionamentos de generalização e especialização entre as entidades, atribuindo propriedades às classes gerais, subclasses, sub subclasses (Campos \& Gomes, 2008).

Desta forma, a taxonomia é um instrumento da organização e representação do conhecimento. Pode ser entendida como um conjunto de termos estruturados tradicionalmente de forma hierárquica para representar as áreas nas quais são aplicadas por meio de seus termos a fim de ajudar na localização de informação relevante, pois permite organizar sistematicamente a informação criando modelos conceituais de determinado domínio.

\section{Inter-relação entre a competência em informação e a organização do conhecimento}

A partir do entendimento sobre competência em informação e organização do conhecimento desenvolveu-se um quadro de inter-relação entre os padrões e indicadores Belluzzo (2007), com as categorias de domínio cognitivo ou Taxonomia de Bloom que representam etapas a serem cumpridas no processo de organização do conhecimento e uma exemplificação da atuação do profissional da informação.

A Taxonomia de Bloom foi desenvolvida de modo a hierarquizar os objetivos educacionais definidos por cognitivo (aprendizagem), afetivo (sensibilização e emoções) e psicomotor (execução das tarefas do aparelho motor). Utilizou-se o domínio cognitivo porque a Competência em Informação é conceituada pela aprendizagem ao longo da vida pelos pesquisadores da área.

Já os padrões e indicadores Belluzzo são explicados por Belluzzo e Kerbauy (2004, p.139),

Padrões e indicadores de desempenho aqui apresentados estão sendo lançados, em base inicial, a fim de que grupos de trabalhos, educadores, gestores e instituições responsáveis por programas de educação em todos os níveis, os identifiquem e aperfeiçoem. Espera-se que esta contribuição possa ser de utilidade para o despertar de novos estudos e pesquisas na área, considerando-se os cenários da sociedade do conhecimento e as perspectivas de aprendizado ao longo da vida, características marcantes deste novo milênio (Belluzzo \& Kerbauy, 2004, p.139).

A competência em informação e a organização do conhecimento são assuntos estudados de maneira segregada pela ciência da informação, entretanto, defende-se nesse trabalho que sua inter-relação é relevante e contribui com a prática do profissional da informação de modo a concretizar a interdisciplinaridade.

Morin (2002, p. 195) é um autor que reforça a importância da interdisciplinaridade ao afirmar que: "as disciplinas se fecharam sobre objetos mutilados. Assim, o conhecimento fechado destruiu ou ocultou em toda a parte as solidariedades, as articulações, a ecologia dos seres e dos atos, a existência”.

A interdisciplinaridade relaciona as disciplinas a fim de ambas contribuam para o desenvolvimento da outra, conforme explica Reis (2005, p. 5):

Num sentido profundo, a interdisciplinaridade é sempre uma reação alternativa à abordagem disciplinar normalizada (seja no ensino ou na pesquisa) dos diversos objetos de estudo. Existem sempre, portanto, várias reações interdisciplinares possíveis para um mesmo desafio do conhecimento, no presente trabalho será aplicado a inter-relação. Como base para executar essa inter-relação, entende-se que a ciência da informação é uma área interdisciplinar e que essa interdisciplinaridade é fundamental para produção de novos conhecimentos dentro da própria área.

A construção da Ciência da Informação é profundamente relacionada à sua natureza interdisciplinar, pois no princípio as relações interdisciplinares não estavam bem definidas, as conceituações teóricas e epistemológicas da área necessitam ainda de mais estudos (Pinheiro, 2002).

Pinheiro (1997) discorre que a interdisciplinaridade é a integração dos resultados ou de esquemas conceituais de disciplinas diferentes. E em 2006 a autora relata que a interdisciplinaridade ainda precisa ser mais abordada, uma vez que quando se estuda interdisciplinaridade outros conceitos emergem, como campo e área, ou como aplicações.

Pombo (2005) caracteriza os termos pluridisciplinaridade, multidisciplinaridade, interdisciplinaridade e transdisciplinaridade como mais ou menos equivalentes. Para definição desses quatro termos, ela afirma que é necessário reconhecer que por detrás dessas palavras multi, pluri, inter e transdisciplinaridade, sempre há a mesma raiz, que é a palavra disciplina. Desta forma, entende-se que o sufixo é a ultrapassagem daquilo que é próprio da disciplina, assim as disciplinas pretendem juntar-se ou pô-las lado a lado no sentido de "multi, pluri". Ou supõe um sentido de ir mais além, transpassar, transformar, usando o sufixo "trans". Ou então estabelecer uma ação recíproca de inter-relação no sentido de "inter", a interdisciplinaridade passa pelo interior de cada disciplina e proporciona cruzamentos conceituais, hipóteses, metodologias e resultados e essa inter-relação possibilita atingir camadas mais profundas da realidade que se quer estudar.

Desta forma, nesse artigo foi utilizado a interdisciplinaridade para realizar a inter-relação entre a Competência em Informação, representada pelos Padrões Belluzzo e a Organização e Representação do Conhecimento, representada pelas Categorias da Taxonomia de Bloom (apêndices), a fim de colaborar com a atuação do profissional da informação no momento do processo de organização e representação do conhecimento para proporcionar ao usuário melhor acesso e uso da informação, que leva a aprendizagem ao longo da vida, sen- 
do este o principal interesse da competência em informação, ambos dentro da própria Ciência da Informação.

A inter-relação proposta entre o padrão Belluzzo 1 que determina a natureza e a extensão da necessidade de informação relaciona a categoria do conhecimento da Taxonomia de Bloom, aplicado na atividade de organização do conhecimento, e auxilia a determinar as necessidades informacionais para uma análise geral dos assuntos a serem organizados. Com isso, toma-se conhecimento dos temas para realizar uma adequada representação.

O padrão 2 aborda que a pessoa competente em informação acessa a informação necessária com efetividade, relacionando-a com a categoria de compreensão. Essa inter-relação contribui para uma busca dos assuntos para encontrar o termo que melhor possa representar os documentos. Logo, passa a compreender, de maneira geral, o conteúdo e conceitos desses temas.

O padrão 3 permite avaliar criticamente a informação e as suas fontes, relacionadas com a categoria de aplicação. Este padrão verifica a qualidade das fontes de informação, bem como sua ideologia aplicando seus conhecimentos no processo de organização do conhecimento.

O padrão 4 admite o uso da informação com efetividade para alcançar um objetivo/obter um resultado. Sua inter-relação com a categoria de análise colabora para atividade de organização do conhecimento em que o conhecimento que também foi adquirido na análise dos temas e conteúdos, quando utilizado na representação, classificação e indexação dos documentos, disponibilize adequadamente os documentos que facilitam o acesso e uso da informação.

O padrão 5 possibilita que a pessoa competente em informação compreenda as questões econômicas, legais e sociais da ambiência do uso da informação e acesse e use a informação ética e legalmente. A categoria de síntese e avaliação contribui com a atividade de organização do conhecimento, em que é fundamental realizar uma síntese dos termos selecionados para representação e relacioná-los com questões econômicas, legais e sociais da ambiência do uso da informação, pois pode haver particularidades legais e culturais de biblioteca para biblioteca, dependendo de seu tipo, contexto, localidade e outras especificidades. Essa síntese também contribui para realizar uma avaliação para constatar possíveis falhas durante o processo de organização do conhecimento.

Bloom dividiu o domínio afetivo em cinco ações que descrevem a sensibilização do indivíduo em relação aos valores que também podem ser relacionados com a competência em informação, já que para buscar e usar determinada informação a pessoa se sente motivada, portanto considera-se o domínio subjetivo, conforme o quadro 3 (explicitado no apêndice).

\section{Considerações Finais}

A pesquisa teórico-reflexiva, de cunho exploratória, visou verificar a inter-relação entre os padrões e indicadores Belluzzo e a Taxonomia de Bloom realizada a partir dos conceitos de competência em informação, organização do conhecimento, padrões e indicadores Belluzzo e Taxonomia de Bloom. O estudo contribuiu de forma significativa para responder ao problema de pesquisa proposto, explicitado por meio do quadro 1 no qual houve uma inter-relação entre os padrões Belluzzo (2007), as categorias da Taxonomia de Bloom e a atuação do profissional da informação para atender as necessidades dos usuários.

Com isso compreende-se que o profissional competente da informação realiza a organização do conhecimento de forma propícia e ainda estimula uma avaliação de todo o processo para se identificar seus possíveis erros. Assim, a informação e o conhecimento podem ser acessados, avaliados e usados de maneira inteligente e eficaz e com isso a unidade de informação se torna um espaço de aprendizado ao longo da vida.

\section{Notas}

(1) Embora a denominação "profissional da informação" seja ampla e abarque várias profissões, nesse trabalho profissional da informação refere-se, na maior parte das vezes, ao bibliotecário.

\section{References}

Barité, Mario. Organización del conocimiento: un nuevo marco teórico-conceptual en Bibliotecología y Documentación. // CARRARA, K. (Org.). Educação, Universidade e Pesquisa. Marília: Unesp-Marília-Publicações; São Paulo: FAPESP, 2001. p.35-60.

Belluzzo, R. C. B. Construção de Mapas: desenvolvendo competências em informação e comunicação. Bauru: Cá entre nós, 2007.

Belluzzo, R. C. B.; Kerbauy, M. T. M. Em busca de parâmetros de avaliação da formação contínua de professores do ensino fundamental para o desenvolvimento da Information Literacy. // Educação Temática Digital, Campinas, v.5, n.2, p.129-139, jun. 2004.

Campos, Maria Luiza; Gomes, Hagar E. Taxonomia e classificação: o princípio de categorização. // DataGramaZero, v. 9, n. 4, ago. 2008.

Dudziak, E. A. Information Literacy: princípios, filosofia e prática. // Ciência da Informação, Brasília, v. 32, n. 1, p.23-35, abr. 2003.

Hjorland, Birger. Fundamentals of knowledge organization. // Knowledge Organization, v. 30, n. 2, p. 87-111, 2003.

Lima, J. L. O.; Alvares, L. Organização e representação da informação e do conhecimento. // ALVARES, L. (Org.). Organização da informação e do conhecimento: conceitos, subsídios interdisciplinares e aplicações. São Paulo: B4 Editores, 2012. 248 p. Capítulo 1, p. $21 / 48$.

Mata, M. L. Da; Casarin, H. C. S. Aspectos éticos e legais da competência informacional e a formação do bibliotecário: um estudo

Ottonicar, Selma Letícia Capinzaiki; Moraes, Isabela Santana de, Moreira, Walter. A Competência em Informação como um fator relevante para a Organização do Conhecimento: inter-relação entre padrões Belluzzo e as categorias da Taxonomia de Bloom na organização do conhecimento // Brazilian Journal of Information Studies: Research Trends. 10:3 (2016) 100-111. ISSN 1981-1640. 
com graduandos de bilioteconomia da região sudeste. Revista EDICIC, v.1, n.1, p.119-134, Ene./Mar. 2011. Disponible en:http://www.edicic.org/revista/index.php?journal=RevistaEDI CIC

\&page=article\&op=view $\&$ path $\% 5 \mathrm{~B} \% 5 \mathrm{D}=13 \&$ path $\% 5 \mathrm{~B} \% 5 \mathrm{D}=\mathrm{p}$ df. Acesso em: 2 dez. 2015.

Morin, E. O Método 1. Porto Alegre: Sulina, 2002.

Pinheiro, L. V. R.. Gênese da Ciência da Informação ou sinais anunciadores da nova área. // O campo da Ciência da Informação: gênese, conexões e especificidades. João Pessoa, UFPB, 2002. P.61-86

Pinheiro, Lena Vania Ribeiro. Ciência da Informação entre sombra e luz: domínio epistemológico e campo interdisciplinar. Rio de Janeiro: 1997. 278p. Tese (Comunicação e Cultura) UFRJ/ECO. Orientadora: Gilda Braga. Disponível em: <http://biblioteca.ibict.br/phl8/anexos/lenavaniapinheiro 1997.pdf>.

Pombo, Olga. Interdisciplinaridade e integração dos saberes. // LIINC em Revista, v.1, n.1, p.3-15, mar., 2005. Disponível em: $\langle$ http://revista.ibict.br/liinc/index.php/liinc >.

Reis, H. R. Sobre o Conceito de Interdisciplinaridade. // Cadernos de Pesquisa interdisciplinar em Ciências Humanas. Florianópolis:
Santa Catarina, Vol. 6, n. 76, p-1-23, 2005. Disponível em: < https://periodicos.ufsc.br/index.php/cadernosdepesquisa/article/v iew/2176/4455>. Acesso em: $11 \mathrm{dez}, 2015$.

Vitorino, E. V. Piantola, D. Competência informacional- bases históricas e conceituais: construindo significados. // Ciência da Informação, Brasília, DF, v. 38, n. 3, p. 130-141, set./dez., 2009.

Copyright: (C) 2016 Ottonicar (et al.). This is an openaccess article distributed under the terms of the Creative Commons CC Attribution-ShareAlike (CC BYSA), which permits use, distribution, and reproduction in any medium, under the identical terms, and provided the original author and source are credited. 
Apêndices

PADRÃO 1 - A pessoa competente em informação determina a natureza e a extensão da necessidade de informação

Indicador de Desempenho

1.1 Define e reconhece a necessidade de informação

Resultados Desejáveis

1.1.1 Identifica um tópico de pesquisa ou outra informação necessária

1.1.2 Formula questões apropriadas baseado na informação necessária ou tópico de pesquisa

1.1.3 Usa fontes de informação gerais ou específicas para aumentar o seu conhecimento sobre o tópico

1.1.4 Modifica a informação necessária ou o tópico de pesquisa para concluir o foco sob controle.

1.1.5 Identifica conceitos e palavras-chave que representam a informação necessária ou o tópico de pesquisa/questão.

Indicador de Desempenho

1.2 Identifica uma variedade de tipos e formatos de fontes de informação potenciais

Resultados Desejáveis

1.2.1 Identifica o valor e as diferenças de potencialidades de fontes em uma variedade de formatos (documentos impressos e eletrônicos, pessoas, instituições, etc.)

1.2.2 Identifica o propósito e o tipo de informação a que se destinam as fontes

1.2.3 Diferencia fontes primárias e secundárias, reconhecendo o seu uso e a sua importância para cada área específica Indicador de Desempenho

1.3 Considera os custos e benefícios da aquisição da informação necessária

Indicador de Desempenho

1.3 Considera os custos e benefícios da aquisição da informação necessária

Resultados Desejáveis

1.3.1 Determina a disponibilidade da informação necessária e toma decisões sobre as estratégias de pesquisa da informação e o uso de serviços de informação e qual a mídia adequada (por exemplo: intercâmbio, utilização de fontes locais, obtenção de imagens, vídeos, textos ou registros sonoros, etc.)

1.3.2 Determina um planejamento exequível e um cronograma adequado para a obtenção da informação necessária.

PADRÃO 2 - A pessoa competente em informação acessa a informação necessária com efetividade

Indicador de Desempenho

2.1 Seleciona os métodos mais apropriados de busca e/ou sistemas de recuperação da informação para acessar a informação necessária.

Resultados Desejáveis

2.1.1 Identifica os tipos de informação contidos em um sistema tradicional e os tipos de fontes indexadas eletronicamente

2.1.2 Seleciona apropriadamente os sistemas de recuperação de informação para pesquisar o problema/tópico baseado na investigação da sua abrangência, conteúdo, organização e solicita ajuda para pesquisar em diferentes instrumentos como as bases de dados, fontes de referência e outras.

2.1.3 Identifica outros métodos de pesquisa para obter a informação necessária, os quais podem não estarem disponíveis por meio dos sistemas de recuperação da informação tradicionais e eletrônicos (por exemplo: necessidade de fazer entrevistas com especialistas, etc.)

Indicador de Desempenho

2.2 Constrói e implementa estratégias de busca delineadas com efetividade.

Resultados Desejáveis

2.2.1 Desenvolve um plano de pesquisa apropriado aos sistemas de recuperação da informação e/ou método de pes-

Ottonicar, Selma Letícia Capinzaiki; Moraes, Isabela Santana de, Moreira, Walter. A Competência em Informação como um fator relevante para a Organização do Conhecimento: inter-relação entre padrões Belluzzo e as categorias da Taxonomia de Bloom na organização do conhecimento // Brazilian Journal of Information Studies: Research Trends. 10:3 (2016) 100-111. ISSN 1981-1640. 
quisa.

2.2.2 Identifica palavras-chave, frases, sinônimos e termos relacionados com a informação necessária

2.2.3 Seleciona vocabulário controlado específico como instrumento de pesquisa e identifica quando o vocabulário controlado é usado em um item registrado e executa a pesquisa com sucesso usando adequadamente o vocabulário selecionado.

2.2.4 Constrói e implementa uma estratégia de busca usando códigos e comandos de acordo com o sistema de recuperação de informação utilizado (por exemplo: a lógica booleana, ordem alfabética de termos, referência cruzada, etc.)

2.2.5 Utiliza a autoajuda dos sistemas de recuperação e outros meios (por exemplo: profissionais da informação) para melhorar os seus resultados.

Indicador de Desempenho

2.3 Busca a informação via eletrônica ou com pessoas utilizando uma variedade de métodos.

Resultados Desejáveis

2.3.1 Usa vários sistemas de recuperação da informação em uma variedade de formatos (impressos e eletrônicos

2.3.2 Distingue pelas citações os vários tipos de documentos (por exemplo: livros, periódicos, teses, etc.)

2.3.3 Utiliza vários esquemas de classificação ou outros sistemas para localizar as fontes de informação junto aos serviços de informação.

2.3.4 Utiliza serviços on-line ou pessoas especializadas disponíveis na instituição para recuperar a informação necessária

Indicador de Desempenho

2.4 A pessoa competente em informação retrabalha e melhora a estratégia de busca quando necessário

Resultados Desejáveis

2.4.1 Avalia a quantidade, qualidade e relevância dos resultados da pesquisa para determinar sistemas alternativos de recuperação da informação ou métodos de pesquisa ainda precisam ser usados.

2.4.2 Identifica lacunas na informação necessária face aos resultados da pesquisa

2.4.3 Revisa a estratégia de busca se for necessário obter mais informação.

Indicador de Desempenho

2.5 A pessoa competente em informação extrai, registra e gerencia a informação e suas fontes

Resultados Desejáveis

2.5.1 Registra todas as informações com as citações pertinentes para futura referenciação bibliográfica

2.5.2 Demonstra compreender como organizar e tratar a informação obtida

2.5.3 Diferencia entre os tipos de fontes citadas e compreende os elementos e a forma correta de citação para os vários tipos de fontes de acordo com as normas de documentação vigentes

Padrão 3 - A pessoa competente em informação avalia criticamente a informação e as suas fontes

Indicador de Desempenho

3. 1 Demonstra conhecimento da maior parte das ideias da informação obtida

Resultados Desejáveis

3.1.1 Seleciona a informação relevante baseado na compreensão das ideias contidas nas fontes de informação

3.1.2 Reformula conceitos com suas próprias palavras

3.1.3 Identifica textualmente a informação que foi adequadamente transcrita ou parafraseada

Indicador de Desempenho

3.2 Articula e aplica critérios de avaliação para a informação e as fontes

Resultados Desejáveis

Ottonicar, Selma Letícia Capinzaiki; Moraes, Isabela Santana de, Moreira, Walter. A Competência em Informação como um fator relevante para a Organização do Conhecimento: inter-relação entre padrões Belluzzo e as categorias da Taxonomia de Bloom na organização do conhecimento // Brazilian Journal of Information Studies: Research Trends. 10:3 (2016) 100-111. ISSN 1981-1640. 
3.2.1 Examina e compara a informação de várias fontes para avaliar a sua confiabilidade, validade, precisão, autoridade, atualidade e ponto de vista ou tendências

3.2.2 Analisa a lógica da argumentação da informação obtida

3.2.3 Reconhece e descreve os vários aspectos de uma fonte, seus impactos e valor para o projeto de pesquisa, assim como as tendências e impactos relacionados a pressupostos de ordem cultural, geográfica ou histórica e/ou atualidade da fonte de informação

3.2.4 Demonstra a habilidade de encontrar a informação sobre a autoridade e qualificação de autores e/ou editoresprodutores

3.2.5 Demonstra compreensão e habilidade para interpretar referências bibliográficas ou créditos encontrados nas fontes como meios de acessar informação precisa e válida

3.2.6 Demonstra compreensão da necessidade de verificar a precisão e completeza de dados ou fatos

Indicador de Desempenho

3.3 Compara o novo conhecimento com o conhecimento anterior para determinar o valor agregado, contradições ou outra característica da informação

Resultados Desejáveis

3.3.1 Determina se a informação obtida é suficiente e adequada ou se é necessário obter mais informação

3.3.2 Avalia se as fontes de informação são contraditórias

3.3.3 Compara a nova informação com o conhecimento próprio e outras fontes consideradas como autoridade no assunto para conclusões

3.3.4 Seleciona a informação que traz evidências para o problema /tópico de pesquisa ou outra informação necessária

Padrão 4 - A pessoa competente em informação, individualmente ou como membro de um grupo, usa a informação com efetividade para alcançar um objetivo/obter um resultado.

Indicador de Desempenho

4.1 É capaz de sintetizar a informação para desenvolver ou completar um projeto

Resultados Desejáveis

4.1.1 Organiza a informação, utilizando esquemas ou estruturas diversas

4.1.2 Demonstra compreender como usar as citações ou paráfrases de um autor ou texto para apoiar as ideias e/ou argumentos (ver também 3.1.2 e 3.1.3)

Indicador de Desempenho

4.2 Comunica os resultados do projeto com efetividade

Resultados Desejáveis

4.2.1 Utiliza adequadamente as normas de documentação e o formato e estilo apropriados para um projeto científico (ver também 5.3.1)

Padrão 5 - A pessoa competente em informação compreende as questões econômicas, legais e sociais da ambiência do uso da informação e acessa e usa a informação ética e legalmente

Indicador de Desempenho

5.1 Demonstra compreensão sobre as questões legais, éticas e socioeconômicas que envolvem a informação, a comunicação e a tecnologia

Resultados Desejáveis

5.1.1 Identifica e discute questões relacionadas ao livre acesso versus o acesso restrito e o pagamento de serviços de informação e comunicação

5.1.2 Demonstra compreensão acerca das questões ligadas ao direito nacional e internacional de propriedade intelectual e as leis de imprensa

5.1.3 Define e identifica exemplos de plágio

5.1.4 Demonstra conhecer as políticas institucionais sobre o plágio e os direitos autorais

Indicador de Desempenho

5.2 Cumpre as leis, regulamentos, políticas institucionais e normas relacionadas ao acesso e uso às fontes de informação

Ottonicar, Selma Letícia Capinzaiki; Moraes, Isabela Santana de, Moreira, Walter. A Competência em Informação como um fator relevante para a Organização do Conhecimento: inter-relação entre padrões Belluzzo e as categorias da Taxonomia de Bloom na organização do conhecimento // Brazilian Journal of Information Studies: Research Trends. 10:3 (2016) 100-111. ISSN 1981-1640. 
Resultados Desejáveis

5.2.1 Utiliza adequadamente os passwords para acesso às fontes de informação

5.2.2 Obedece às políticas institucionais de acesso às fontes de informação

5.2.3 Preserva a integridade das fontes de informação, equipamentos sistemas e instrumentos disponibilizados para o acesso e uso da informação

5.2.4 Demonstra conhecimento do que é o plágio e como não usá-lo em suas comunicações

5.2.5 Obtém permissão para copiar textos, imagens ou sons incluídos em seu produto final

Indicador de Desempenho

5.3 Indica as fontes de informação nas comunicações do produto ou resultados

Resultados Desejáveis

5.3.1 Utiliza estilo e forma de linguagem e de redação apropriados, com a indicação correta e consistente das fontes consultadas

5.3.2 Identifica elementos de citação para as fontes de informação consultadas em diferentes formatos

5.3.3 Demonstra compreensão das normas de documentação recomendadas para a sua área de pesquisa/ estudo

Quadro 1- Padrões, indicadores e resultados desejáveis da Competência em Informação Fonte: adaptado Belluzzo (2007, p. 95-103)

\begin{tabular}{|c|c|c|}
\hline Padrões Belluzzo & $\begin{array}{l}\text { Categorias da Taxonomia de } \\
\text { Bloom - Domínio cognitivo }\end{array}$ & Atuação do profissional da informação \\
\hline $\begin{array}{l}\text { PADRÃO 1 - A pessoa } \\
\text { competente em informação de- } \\
\text { termina a natureza e a extensão } \\
\text { da necessidade de informação }\end{array}$ & Conhecimento & $\begin{array}{l}\text { O profissional da informação percebe quais } \\
\text { são as necessidades informacionais dos usuá- } \\
\text { rios e com isso toma conhecimento dos prin- } \\
\text { cipais assuntos que contribuem com sua pes- } \\
\text { quisa. }\end{array}$ \\
\hline $\begin{array}{l}\text { PADRÃO 2 - A pessoa } \\
\text { competente em informação aces- } \\
\text { sa a informação necessária com } \\
\text { efetividade }\end{array}$ & Compreensão & $\begin{array}{l}\text { O profissional da informação realiza uma bus- } \\
\text { ca dos temas importantes para os usuários de } \\
\text { forma eficaz e com isso passa a compreender, } \\
\text { de maneira geral, o conteúdo desses conceitos. }\end{array}$ \\
\hline $\begin{array}{l}\text { Padrão } 3-\text { A pessoa } \\
\text { competente em informação ava- } \\
\text { lia criticamente a informação e } \\
\text { as suas fontes }\end{array}$ & Aplicação & $\begin{array}{l}\text { O profissional da informação verifica a quali- } \\
\text { dade das fontes de informação, bem como } \\
\text { sua ideologia aplicando seus conhecimentos } \\
\text { no processo de organização do conhecimento. }\end{array}$ \\
\hline $\begin{array}{l}\text { Padrão } 4-\text { A pessoa } \\
\text { competente em informação, in- } \\
\text { dividualmente ou como membro } \\
\text { de um grupo, usa a informação } \\
\text { com efetividade para alcançar } \\
\text { um objetivo/obter um resultado. }\end{array}$ & 4-Análise & $\begin{array}{l}\text { Nessa etapa o profissional da informação } \\
\text { compartilha as informações por meio da dis- } \\
\text { ponibilização dos conhecimentos a partir de } \\
\text { uma análise de seu conteúdo para que o usuá- } \\
\text { rio consiga atingir os seus objetivos de uso da } \\
\text { informação. }\end{array}$ \\
\hline $\begin{array}{l}\text { Padrão } 5-\text { A pessoa } \\
\text { competente em informação } \\
\text { compreende as questões econô- } \\
\text { micas, legais e sociais da ambi- } \\
\text { ência do uso da informação e } \\
\text { acessa e usa a informação ética e } \\
\text { legalmente. }\end{array}$ & Síntese e avaliação & $\begin{array}{l}\text { A partir das categorias/etapas descritas é fun- } \\
\text { damental realizar uma síntese dos conceitos e } \\
\text { relacioná-los com as questões éticas e legais } \\
\text { do uso da informação e posteriormente, fazer } \\
\text { uma avaliação dos resultados para constatar } \\
\text { possíveis falhas durante o processo de organi- } \\
\text { zação do conhecimento (feedback). }\end{array}$ \\
\hline
\end{tabular}

Ottonicar, Selma Letícia Capinzaiki; Moraes, Isabela Santana de, Moreira, Walter. A Competência em Informação como um fator relevante para a Organização do Conhecimento: inter-relação entre padrões Belluzzo e as categorias da Taxonomia de Bloom na organização do conhecimento // Brazilian Journal of Information Studies: Research Trends. 10:3 (2016) 100-111. ISSN 1981-1640. 
Quadro 2: Inter-relação entre padrões Belluzzo, domínio cognitivo da Taxonomia de Bloom e a atuação do profissional da informação

\begin{tabular}{|c|c|c|}
\hline $\begin{array}{l}\text { Padrões, indicadores e resul- } \\
\text { tados desejáveis Belluzzo }\end{array}$ & $\begin{array}{l}\text { Categorias da Taxonomia de } \\
\text { Bloom - Domínio afetivo }\end{array}$ & Atuação do profissional da informação \\
\hline $\begin{array}{l}\text { 1.1 Define e reconhece a neces- } \\
\text { sidade de informação; } \\
1.2 \text { Identifica uma variedade de } \\
\text { tipos e formatos de fontes de } \\
\text { informação potenciais; e } \\
\text { 1.3 Considera os custos e bene- } \\
\text { fícios da aquisição da informa- } \\
\text { ção necessária. }\end{array}$ & $\begin{array}{ll}1- & \text { Recepção }\end{array}$ & $\begin{array}{l}\text { O profissional da informação tem uma moti- } \\
\text { vação e por isto reconhece a necessidade de } \\
\text { informação do usuário, idêntica as fontes po- } \\
\text { tenciais e considera os benefícios da informa- } \\
\text { ção para o usuário. Portanto deve ser recepti- } \\
\text { vo as novas formas de busca de informação no } \\
\text { processo de organização do conhecimento. }\end{array}$ \\
\hline $\begin{array}{l}\text { 2.1 Seleciona os métodos mais } \\
\text { apropriados de busca e/ou siste- } \\
\text { mas de recuperação da informa- } \\
\text { ção para acessar a informação } \\
\text { necessária; } \\
2.2 \text { Constrói e implementa estra- } \\
\text { tégias de busca delineadas com } \\
\text { efetividade; } \\
2.3 \text { Busca a informação via ele- } \\
\text { trônica ou com pessoas utilizan- } \\
\text { do uma variedade de métodos; } \\
2.4 \text { A pessoa competente em } \\
\text { informação retrabalha e melhora } \\
\text { a estratégia de busca quando } \\
\text { necessário; e } \\
2.5 \text { A pessoa competente em } \\
\text { informação extrai, registra e ge- } \\
\text { rencia a informação e suas fontes }\end{array}$ & Resposta & $\begin{array}{l}\text { A partir da motivação inicial o profissional } \\
\text { cria um mecanismo de resposta a necessidade } \\
\text { de informação, principalmente ao selecionar } \\
\text { os métodos e estratégias de busca, acessa a } \\
\text { informação eletronicamente e por meio das } \\
\text { pessoas, analisa a estratégia e a modifica } \\
\text { quando necessário, extraí e gerencia as fontes } \\
\text { de informação segundo a utilização que será } \\
\text { feita pelo usuário. }\end{array}$ \\
\hline $\begin{array}{l}\text { 3. 1 Demonstra conhecimento da } \\
\text { maior parte das ideias da infor- } \\
\text { mação obtida; } \\
\text { 3.2 Articula e aplica critérios de } \\
\text { avaliação para a informação e as } \\
\text { fontes; } \\
\text { 3.3 Compara o novo conheci- } \\
\text { mento com o conhecimento an- } \\
\text { terior para determinar o valor } \\
\text { agregado, contradições ou outra } \\
\text { característica da informação; } \\
\text { 4.1 É capaz de sintetizar a in- } \\
\text { formação para desenvolver ou } \\
\text { completar um projeto; e } \\
\text { 4.2 Comunica os resultados do } \\
\text { projeto com efetividade }\end{array}$ & Valorização & $\begin{array}{l}\text { Depois, o profissional da informação analisa o } \\
\text { conteúdo da informação que obteve, conhece e } \\
\text { valoriza a informação, avalia as fontes segun- } \\
\text { do sua qualidade e confiabilidade se utilizam } \\
\text { de seus próprios conhecimentos para agregar } \\
\text { na informação, sintetiza a informação e a dis- } \\
\text { semina de maneira eficaz. }\end{array}$ \\
\hline $\begin{array}{l}2.5 \text { A pessoa competente em } \\
\text { informação extrai, registra e ge- } \\
\text { rencia a informação e suas fon- } \\
\text { tes; } \\
2.5 .2 \text { Demonstra compreender } \\
\text { como organizar e tratar a infor- }\end{array}$ & Organização & $\begin{array}{l}\text { Ao entender a importância da informação é } \\
\text { importante gerenciar as fontes de modo a or- } \\
\text { ganizar e tratar a informação. Compreende } \\
\text { como citar os diferentes documentos e fontes } \\
\text { escolhidos de acordo com o critério de análise } \\
\text { e classifica as obras bem como as fontes in- }\end{array}$ \\
\hline
\end{tabular}

Ottonicar, Selma Letícia Capinzaiki; Moraes, Isabela Santana de, Moreira, Walter. A Competência em Informação como um fator relevante para a Organização do Conhecimento: inter-relação entre padrões Belluzzo e as categorias da Taxonomia de Bloom na organização do conhecimento // Brazilian Journal of Information Studies: Research Trends. 10:3 (2016) 100-111. ISSN 1981-1640. 


\begin{tabular}{|c|c|c|}
\hline $\begin{array}{l}\text { mação obtida; } \\
\text { 2.5.3 Diferencia entre os tipos de } \\
\text { fontes citadas e compreende os } \\
\text { elementos e a forma correta de } \\
\text { citação para os vários tipos de } \\
\text { fontes de acordo com as normas } \\
\text { de documentação vigentes; e } \\
\text { 4.1.1 Organiza a informação, } \\
\text { utilizando esquemas ou estrutu- } \\
\text { ras diversas. }\end{array}$ & & formação. \\
\hline $\begin{array}{l}\text { 4.2.1 Utiliza adequadamente as } \\
\text { normas de documentação e o } \\
\text { formato e estilo apropriados para } \\
\text { um projeto científico; } \\
5.1 \text { Demonstra compreensão } \\
\text { sobre as questões legais, éticas e } \\
\text { socioeconômicas que envolvem } \\
\text { a informação, a comunicação e a } \\
\text { tecnologia; } \\
5.2 \text { Cumpre as leis, regulamen- } \\
\text { tos, políticas institucionais e } \\
\text { normas relacionadas ao acesso e } \\
\text { uso às fontes de informação; e } \\
5.3 \text { Indica as fontes de informa- } \\
\text { ção nas comunicações do produ- } \\
\text { to ou resultados. }\end{array}$ & $\begin{array}{l}\text { 5- } \quad \text { Internalização de valo- } \\
\text { res }\end{array}$ & $\begin{array}{l}\text { Uma vez que houve motivação, resposta, valo- } \\
\text { rização e organização, o profissional da infor- } \\
\text { mação internaliza os valores e normas para } \\
\text { realizar a documentação da atividade de orga- } \\
\text { nização do conhecimento, aplicando as ques- } \\
\text { tões legais e éticas relacionadas com a infor- } \\
\text { mação e o conhecimento produzido, respeita } \\
\text { as normas de propriedade intelectual e paten- } \\
\text { tes, indicando as fontes de informação no re- } \\
\text { sultado final do processo de organização do } \\
\text { conhecimento. }\end{array}$ \\
\hline
\end{tabular}

Quadro 3 - Inter-relação entre Indicadores Belluzzo, domínio afetivo da Taxonomia de Bloom e a atuação do profissional da informação 